\title{
Impact of Internally Displaced Persons on Forest and Vegetation of Jere LGA, Borno State, Nigeria
}

\author{
${ }^{*}$ MUSA, A; ${ }^{2}$ IBRAHIM, MB; ${ }^{3}$ ALIYU, A; ${ }^{1}$ ALI, FA \\ ${ }^{*}$ Department of Basic Science, Mohamet Lawan College of Agriculture Maiduguri, P.M.B.1427, Maiduguri, Borno State, Nigeria. \\ *Corresponding Author Email: abbakmusa@ gmail.com; Tel: 08184043424 \\ ${ }^{2}$ Department of Geography, University of Maiduguri, P.M.B. 1069 Maiduguri, Borno State, Nigeria. Email: mbellodk@unimaid.edu.ng \\ ${ }^{3}$ Department of Forestry Technology, Mohamet Lawan College of Agriculture Maiduguri, P.M.B.1427, Maiduguri, Borno State, Nigeria. \\ Email: abubakar82aliyu@gmail.com \\ ${ }^{1}$ Department of Basic Science, Mohamet Lawan College of Agriculture, P.M.B.1427 Maiduguri, Maiduguri, Borno State, Nigeria.
}

\begin{abstract}
Deforestation is described as changes in the structure and composition of an area of forest after there has been some form of human intervention such as firewood, charcoal and logging. The study examined impact of internally displaced persons (IDPs) on forest and vegetation cover of Jere L.G.A. of Borno State, Nigeria. The objectives of the study were to determine the extent of impact of deforestation and depletion of vegetation cover caused by displaced persons to forest of Jere L.G.A. and also identifies the socio-economic needs of the displaced persons in camps. Data were collected from both primary and secondary sources. Primary data were generated through field observation and focused group discussion with displaced persons, while the secondary data was obtained from relevant available literature. Findings revealed that about 12 square kilometers of forest and vegetation cover were destroyed by displaced persons. The Findings also revealed that displaced persons engaged in cutting of trees for shelter, firewood, charcoal and debarking trees for medicinal purpose to earn money. The study revealed displaced persons conditioned in camps are deplorable far from the ideal situation. The study concluded that environmental impact assessment should be incorporated in the strategies for displaced persons welfare before their arrival. The study recommended that host governments, humanitarian agencies and NGOs should support the living conditions of displaced persons through socio-economic, education, skill and vocational training development that promotes lifelong learning opportunities.
\end{abstract}

DOI: https://dx.doi.org/10.4314/jasem.v23i5.9

Copyright: Copyright $\odot 2019$ Musa et al. This is an open access article distributed under the Creative Commons Attribution License (CCL), which permits unrestricted use, distribution, and reproduction in any medium, provided the original work is properly cited.

Dates: Received: 28 March 2019; Revised: 12 May 2019; Accepted 23 May 2019

Keywords: Displaced persons, Deforestation, Vegetation, Firewood and Charcoal

Hundreds of thousands of people are displaced due to conflict every year globally (UNHCR, 2010). People were forced to flee from their homes in search of protection, some are able to found refuge with families and friends, but are crowded into camps where they became victims of further violence, mental stress and disease (IDMC, 2012). As near the end of 2013, more than 28.8 million people were internally displaced by conflict and violence across the world with more than 3.5 million people being nearly displaced as a result of violence accompanying the "Arab Spring "uprising in Syria (Khan, 2014). The largest increase in these instances was in the Middle East and North Africa where 2.5 million people forced to flee their homes (UNHCR, 2010). The definition of internally displaced persons (IDPs) use in this study was based on the working description of the United Nation Guiding Principles on Internally Displacement: Internally displaced persons are persons or groups of persons who have been forced or obliged to flee or leave their homes or places of habitual residence, in particular as a result of or in order to avoid the effects of armed conflict, situations of generalized violence, violations of human right or natural or human-made disaster, and who have not crossed an internationally recognized state border (Oucho, 2007). Boko Haram insurgency has become the major problem facing Nigerians in the present time. These groups have perpetrated several bombings that have killed thousands of innocent citizens of this country, Nigeria and also caused destruction of both private and public properties worth billions of naira. In Borno State, two thirds of the 27 Local Government Areas were affected by the insurgency and the State Emergency Management Agency (SEMA) had registered about 111,388 displaced persons in 11 camps (SEMA, 2016). Deforestation is any activity that disrupts the natural ecology of forest as a result of agricultural, social and economic activities carried out in the name of development Ibrahim et al., (2015). It also affects economic activity of forest depended people by reducing the supply of forest products and causes 
siltation, erosion, desertification and drought (Annan, 2013). Rapid deforestation is now a major problem affecting the daily lives of Nigerians through its effects. For instance, between 2000 and 2005, Nigeria lost 5.7 percent of its primary forest as a result of deforestation and the rate continues to 3.8 percent, which is equivalent to 4,000 hectares per annum (Ayala, 2010). The objectives of this study were to determine the extent of the impact of deforestation and vegetation cover caused by the IDPs to the forest of Jere L.G.A. and also to identify the socio-economic needs of the IDPs in their camps.

\section{MATERIAS AND METHOD}

Study Area: Jere Local Government Area is one of the 27 Local Government affected by the insurgency. It shares boundaries with some local government areas; to the northeast shares border with Nganzai and Mafa, while to the southeast shares border with Maiduguri and Konduga and to the northwest shares border with Maiduguri and Konduga.

Data Collection: The study was conducted in April 2016 to January 2017 both primary and secondary sources of data were used. Primary source data generated through field observation and focus group discussions with IDPs. The secondary data were obtained from relevant literature.

Arrival of Displaced Persons into Jere Sub-Urban: Displaced persons flee into Jere sub-urban in fear for their lives, abandoning their assets, their social and family network. The majority of IDPs moved from a rural area to an urban environment, a change that has profound humanitarian economic and social consequences. Displaced persons were first settled in emergency comps such as primary and secondary schools and uncompleted estates that have little or no basic services, such as water, electricity, health care and education. Income earning opportunities were also very difficult most of them were farmers and firewood sellers without access to land nor do they possess alternative skills to earn a decent living.

\section{RESULT AND DISCUSSION}

The study observed that displaced persons exert impact on forest and vegetation which in turn impact on local host communities. IDPs engagement in deforestation was to meet their own survival needs for lumber to build shelter and firewood, and to earn money through selling of firewood and charcoal in both camps and local market. Field visit revealed that almost 4 square kilometers of forest were lost at the hands of 6,377 IDPs of Madinatu 1 and 2 respectively; the IDPs revealed that they have no other means of earning money than to engage in cutting of trees for firewood and sell it. This finding agreed with Thapa and Chapman (2010), in their study on impacts of resource extraction on forest structure and diversity in Bardia National Park, Nepal. Similar situation was observed in the forest not too per from Muna camps 1 and 2 which over 2 square kilometers witnessed massive deforestation at the hands of 4,690 IDPs, it revealed that their engagement in cutting down of trees was to earn money. Field survey to Shuwari forest revealed over exploitation and degradation of natural forest resources, with depleted vegetation cover used for housing construction, firewood and charcoal, debarking trees for medicinal purpose to earn money, about 3 square kilometers of forest were lost. The finding had agreed with Sassen and Shell (2013), in their studies on human impacts on forest structure and species richness on the edges of a protected mountain forest in Uganda.

Table 1: Internally Displaced Persons Camps Sampled for the

\begin{tabular}{ll}
\multicolumn{2}{c}{ Study in Jere L.G.A. } \\
\hline IDPs Camps & Populations of IDPs \\
\hline Madinatu 1 & 3,168 \\
Madinatu 2 & 3,209 \\
Muna $\quad 1$ & 3,268 \\
Muna $\quad 2$ & 1,422 \\
Custom house & 1,847 \\
Shuwari school & 2,173 \\
Muna blind & 2,324 \\
Muna kumburi & 1,634 \\
Fariya & 2,314 \\
Kirbiri & 2,167 \\
Total & 23,526 \\
\hline \multicolumn{2}{c}{ Source Field Survey, 2015 to 2016 }
\end{tabular}

Kirbiri IDPs camp was a self-settlement with a population of 2,167 displaced persons, assisted by the International Committee of Red Cross (ICRC) and World Food Programme (WFP). Finding in the area revealed changes in vegetation and land cover, which depicted declining stands of vegetation along the river Ngadda bank and debarking trees for medicine purpose destroyed about 3 square kilometers of forest. Fuel wood for energy and heating, which is a consequence of deforestation and degradation of land cover, is one area in which IDPs exert a negative impact. This finding agreed with Sasseen and Shell (2013) in their study on human impacts on forest structure and species richness on the edges of a protected mountain forest in Uganda. Field survey in Fariya area revealed that IDPs destroyed vegetation cover along River Ngadda, trees were cut for firewood including economic tree such as destruction of mango orchard, debarking and uprooted many trees to earn money.. 

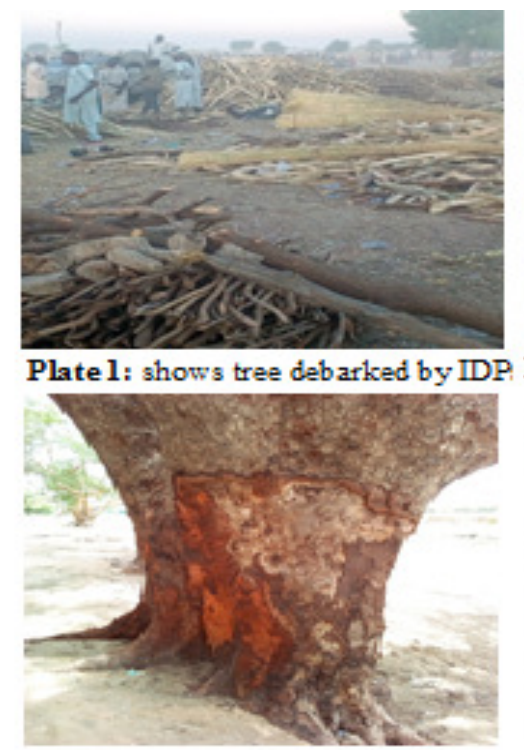

Plate 3: shows local firew ood market

This finding agreed with Mackenzie et al., (2012) in their studies on spatial patterns of illegal resources extraction in Kibale National park, Uganda. IDPs regard forest as an open access resources and so contributed further to their destruction of the forest and vegetation, consequences of their activity was manifested in several forms such as loss of biodiversity and genetic resources, extinction of species, decline in soil nutrient, reduce in transpiration rate and erosion. Vegetation is important to humans as primary sources of food and fuel but these had being over exploited by the IDPs, and demand of forest product is far greater than the supply can meet. The study observed that cutting down of trees for firewood has affected forest cover, particularly in areas supplying firewood to urban areas. Urban use of firewood places heavy pressure on forest resources, especially as urban centre attracts more migrants.

Socio-economic Needs of the Internally Displaced: Persons The insurgency has greatly affected the socioeconomic activities of the displaced persons, particularly agriculture and trading, severely crippled the local economics and increases the vulnerability of entire populations. The displaced communities are mostly rural dwellers were forced to abandon their farms and livestock, which in many cases were taken over by the insurgents. The situation had significantly increased food insecurity levels and had created beggars from communities which before this time were completely independent and even considered wealthy in term of land and livestock ownership. In addition to livelihood, basic food and non-food items remain the highest priority for IDPs. Living conditions in the camps are difficult and in most cases deplorable,

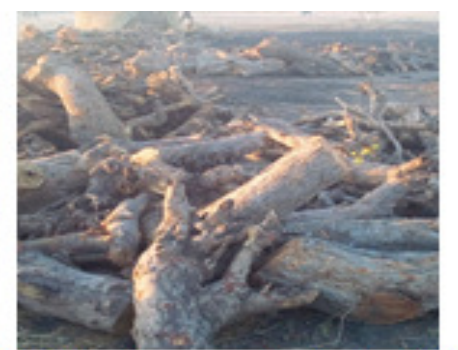

Plate2: shows wood pile for charcoal

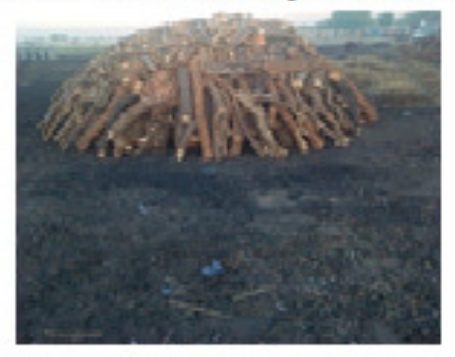

Plate 4: shows parts of trees cut down

mostly due to lack of adequate infrastructure, health facilities, education and security to cater for the populations needs. Despite the humanitarian assistance gotten from SEMA and Non-governmental Organization, IDPs complain that it was inadequate their conditions in the camps are worst far from the ideal situation.

Conclusion: The study concludes that harvesting of forest resources to meet livelihood needs can impact forest regeneration and structure diversity. Environmental impact assessment should be incorporated in the strategies for handling displaced persons welfare. There is a need to establish and understand the state of the environment before the arrival of IDPs and to initiate a preliminary identification, quantification and location of the most degraded areas in order to prioritise areas in need of assistance. The responsibility of taking care of displaced persons welfare should rest with the host governments, humanitarian agencies and NGOs. All policies and interventions should be incorporated to humanitarian with development efforts which will strengthen government programmes that would support the living condition of IDPs in camps. Socioeconomic, education, skill and vocational training development should be provided to displaced persons that promote lifelong learning opportunities.

\section{REFERENCES}

Annan, P (2013). Annual Deforestation Rate and Growth in Gross Domestic Product in Brazil. Nature of Climate Change. 3: 7-9

Ayala, M (2010). Co-integration and Time Series Analysis from Arab Countries Food Gap 1980- 
2001. Journal of Economic and Engineering. 0346 (3): $32-51$

Ibrahim, A (2015). Economic Analysis of Causes and Impact of Deforestation on Agriculture in Nigeria. Journal of Agricultural, Economic, Environment and Social Sciences. 1 (1): 142-150

(IDMC) International Displacement Monitoring Centre (2012). The State of Internally Displaced Persons

Khan, S (2014). Provision Health Assistance to Internally Displaced Persons of South Waziristan Agency in Camps. International Journal of Public Administration and Management Research. 2 (3): 84-97

Sassen, M; Shell, D (2013). Human impacts on Forest Structure and Species Richness on the Edges of a Protected Forest in Uganda. Forest Ecology and Management. 307: 206-218
(SEMA) State Emergency Management Agency (2016). Report on the State of Internally Displaced Persons.

Sims, KR (2010). Conservation and Development: Evidence of Thai Protected Area. Journal of Environmental Economic and Management. 60 (2): $94-14$

Thapa, S; Chapman, DS (2010). Impacts of Resource Extraction on Forest Structure and Diversity in Berdia National Park, Nepal. For. Eco. Manage. 259: 641-649

Oucho, JO (2007). Environmental Impact of Refugees and Internally Displaced Persons in Sub-Saharan Africa. Centre for Research in Ethnic Relations University of Warwick Coventry, CV4 7DL United Kingdom

(UNHCR) United Nations High Commissioner for Refugees (2010). Convention and Protocol Relating to State of Internally Displaced Persons 